\title{
Expressed desire for hastened death by patients with advanced cancer had several meanings and uses
}

Coyle N, Sculco L. Expressed desire for hastened death in seven patients living with advanced cancer: a phenomenologic inquiry. Oncol Nurs Forum 2004;31:699-709.

\section{$Q$ What are the meanings and uses of an expressed desire for hastened death in patients with advanced cancer?}

\section{DESIGN}

Qualitative study using phenomenologic inquiry.

\section{SETTING}

An urban cancer research centre.

\section{PATIENTS}

7 English speaking patients (age range 40-79 y, 4 men) with advanced cancer who had expressed a desire for hastened death on $\geqslant 1$ occasion

\section{METHODS}

Data were collected during a series of 2-6 indepth interviews that lasted 30-60 minutes. Time periods for each interview series ranged from 2 days to 6 months. The interviews were audiotaped and transcribed, and themes were developed through content analysis.

\section{MAIN FINDINGS}

Chronic triggers that preceded the expressed desire for hastened death included debilitating progression of disease; perception of chronic and progressive loss of social support, dignity, autonomy, and sense of worth; and perception of being a burden to self or others in the present or future. Acute events preceding expression of a desire for hastened death included uncontrolled pain, shortness of breath, and medical information that produced fear, hopelessness, and a sense of dread.

9 distinct, but sometimes intertwined and overlapping, meanings and uses of an expressed desire for hastened death were extrapolated from the narratives. (1) A manifestation of the will to live. This theme was named the "primary paradox" because patients' behaviour evidenced the will to live despite having expressed a desire for hastened death on $\geqslant 1$ occasion. For example, "See, there's a problem while planning or pursuing your death... On the one hand, I am saying all these things, and, on the other hand, I am going down for radiation." (2) The process of dying itself was so difficult that an early death was preferred-"the secondary paradox." In these situations, the expression of desire for hastened death reflected that the dying process itself was so difficult that death was better than going through it. (3) The immediate situation was unendurable and required instant action. An expressed desire for hastened death in these situations was an urgent request for help because the immediate situation was unendurable and required instant action (eg, "There were many times when I was in such pain and such misery. I said, let me go...finished...no more of this torture.") (4) A hastened death was an option to extract oneself from an unendurable situation. Severe pain or acute shortness of breath were the 2 symptoms identified as being incompatible with life. (5) A manifestation of the last control the dying person can exert. The expression of desire for hastened death was sometimes an assertion of ultimate control over an untenable

For correspondence: $\mathrm{Dr} \mathrm{N}$ Coyle, Pain and Palliative Care Service Memorial Sloan-Kettering Cancer Center, New York, NY, USA. coylen@ mskcc.org with copy to editor rose_mary@earthlink.net

Source of funding: no external funding. situation. (6) A way of drawing attention to "me as a unique individual." The demand from patients that they be understood and heard as individuals with lives and valued outside of their role as patients was another use of the expression of desire for hastened death. (7) $\mathrm{A}$ gesture of altruism. The desire for hastened death was intended to relieve the family of the burden of care and witnessing the patient's progressive deterioration. (8) An attempt at manipulation of the family to avoid abandonment. For some patients, the expressed desire for hastened death was a message about how dependent they were on those around them. (9) A despairing cry depicting the misery of the current situation. Sometimes the expression of desire for hastened death was an outlet for despair regarding the misery of the current situation.

\section{CONCLUSION}

Expressed desire for hastened death by patients with advanced cancer had several meanings and uses and was an important element of end of life communication.

\section{Commentary}

7 he study by Coyle et al sheds light on different meanings of the expressed desire for hastened death from a patient perspective. An important finding of this study is that a patient's desire for hastened death can be ambivalent. This observation is in agreement with results from other studies describing the process of dying leg, patients near death often appear to have conflicting feelings). ${ }^{2}$ A person who expresses a wish for hastened death can, at the same time, have a strong will to live. Patients' expressions were interpreted as tools of communication. According to Coyle et al, underlying reasons for expressing thoughts about hastened death included a wish to be viewed as a whole person, rather than just a patient, and a wish for alleviation from suffering.

Although the study was described as a phenomenological inquiry, use of the rigorous (and more transparent) method of Giorgi et a $\beta^{\beta}$ could have strengthened the design and findings.

Furthermore, it would have been interesting if Coyle et al had extended the research to focus on patients with a strong wish to die. Sometimes suffering is an underlying reason for requesting assisted suicide. ${ }^{4}$ Some patients hasten their deaths by voluntarily refusing food and fluids. If early intervention can reduce patients' suffering, then research should identify effective methods for clinicians to use. In clinical practice, however, it is important that nurses be open minded and listen to patients' expressions of their experiences, thoughts, and feelings.

Britt-Marie Ternestedt, RN, PhD Department of Health Care Sciences Ersta University College Stockholm, Sweden

1 Weisman AD, Avery D. On dying and denying; a psychiatric study of terminality. New York: Behavioral Publications, 1978

2 Qvarnström U. Patient's reactions to impending death. A clinical study [dissertation]. Stockholm University, Sweden, Stockholm, 1978.

3 Giorgi A, Giorgi B. Phenomenology. In: Smith JA, editor. Qualitative psychology: a practical guide to research methods. London: Sage Publications Ltd, 2003:25-50.

4 Kelly B, Burnett P, Pelusi D, et al. Terminally ill cancer patients' wish to hasten death. Palliat Med 2002;16:339-45. 